\title{
Pemisahan Ion Logam Perak (Ag) dalam Limbah Cair Menggunakan Membran Cair Emulsi (ELM) dengan Senyawa Pembawa Sinergi D2EHPA
}

\author{
Muhammad Cholid Djunaidi1 ${ }^{\star}$, Danang Subarkah Hadikawuryan ${ }^{1}$, \\ Didik Setiyo Widodoํ, Nesti Dwi Maharani ${ }^{1}$
}

${ }^{1}$ Departemen Kimia, Fakultas Sains dan Matematika, Universitas Diponegoro, J1. Prof. Soedarto S.H, Tembalang, Semarang 50275

*Corresponding author: choliddjunaidi@live.undip.ac.id

Received: 23 April 2021 / Accepted: 03 Mei 2021

Available online: 08 Mei 2021

\begin{abstract}
Abstrak
Perak adalah logam yang digunakan secara luas dalam berbagai industri, meliputi fotografi (bahan dasar film dan kertas foto), elektronik, perhiasan, campuran logam (alloy) penghambat korosi, dan sebagainya sampai keskala laboratorium. Kandungan perak dalam limbah sebesar lebih dari 2000 $\mathrm{mg} /$ Lyang berpotensi menyebabkan toksisitas lingkungan dan kesehatan bagi makhluk hidup. Oleh karena itu, perlu dilakukan pemisahan logam perak dalam limbah dengan metode Emulsion Liquid Membrane (ELM) dengan campuran pembawa D2EHPA-TBP yang memiliki efektivitas dan selektivitas yang tinggi terhadap ion logam Ag. Produk perak yang didapatkan sebagai penyedia perak kedua. Hasil yang didapatkan dengan penggunaan pembawa D2EHPA-TBP lebih efektif untuk mengambil perak dari limbah daripada larutan Ag+. Pembawa D2EHPA-TBP menggunakan perak tiosulfat (sinergi) relatif selektif daripada $\mathrm{Cu}(\mathrm{II})$ dan $\mathrm{Cr}(\mathrm{VI})$ dengan persen pengambilan perak sebesar 94,93\%.
\end{abstract}

Kata Kunci: ELM; Logam Perak; selektif; D2EHPA

\section{Pendahuluan}

Perak adalah logam yang digunakan secara luas dalam berbagai industri, meliputi fotografi (bahan dasar film dankertasfoto), elektronik, perhiasan, campuran logam (alloy) penghambat korosi, dan sebagainya sampai keskala laboratorium. Kandungan dalam limbah khususnya perak adalah suatu zat atau bahan kimia berbahaya berbentuk cair/ padat yang berpotensi menyebabkan toksisitas lingkungan dan kesehatan bagi makhluk hidup pada kadar yang tinggi [1] [2] [3]. Logam perak yang masuk dalam tubuh menyebabkan warna abu-abu kulit, membran mukosa, dan mata yang disebut argirosis (argyria). Sejumlah kecil perak nitrat dalam orde $\square$ g dapat menyebabkan kematian bagi ikan dan tumbuhan [4]. Batas minimum kandungan perak dalam limbah sekitar 0,1-1,0 ppm, akan tetapi setelah dianalisis kandungan perak dalam limbah sebesar lebih dari 2000 $\mathrm{mg} / \mathrm{L}$. Perak banyak dimanfaatkan sehingga kebutuhan perak pada masyarakat dunia menjadi tinggi sebesar $25 \%$ dan mengalami peningkatan setiap tahunnya sebesar $2-2,5 \%$ [5] [6] [7]. Oleh karena itu, mengingat toksisitas perak bagi organisme, maka limbah yang mengandung perak sebelum dibuang keperairan harus diolah terlebih dahulu untuk mengambil kembali kandungan peraknya. Salah satu cara untuk mengatasi permasalahan tersebut dengan pemisahan perak dan daur ulang.

Teknik ELM dengan pembawa DDAB (penukar anion) dalam kerosene dan surfaktan SPAN 80 untuk mengambil perak dari limbah cuci/cetakfoto (dalam limbah ini Ag berada dalam bentuk $\left.\mathrm{Ag}\left(\mathrm{S}_{2} \mathrm{O}_{3}\right)_{2}{ }^{3-}\right)$, dengan efisiensi yang kecil hanya $78 \%$ memungkinkan ekstraksi menjadi kurang efektif tanpa pemutusan kompleks $\mathrm{Ag}\left(\mathrm{S}_{2} \mathrm{O}_{3}\right)_{2}{ }^{3}$-sehingga laju difusi menjadi lambat serta dan kurang efektifnya proses stripping yang terjadi [4]. Penelitian mengenai pemisahan logam berat dalam campuran menggunakan metode SLM dengan pembawa D2EHPA dan selektifitas pembawa mengikuti urutan $\mathrm{Ag}>\mathrm{Cu}>\mathrm{Pb}>\mathrm{Ni}>\mathrm{Zn}$ [8]. Penelitian mengenai turunan eugenol sebagai pemisahan ion logam krom (Cr) dari limbah electroplating menggunakan metode Bulk Liquid 
Membrane (BLM), hasil yang didapatkanpersen transport optimal pada fase umpan $\mathrm{pH} 5$ sebesar $101,42 \%$ [9]. Penelitian pemisahan limbah organik dan anorganik menggunakan metode Emulsi Liquid Membrane (ELM) hasil yang diperoleh pada limbah anorganik membran akan membentuk ion logam kompleks, sedangkan pada limbah organik seperti bahan-bahan organik larut dalam pengenceran dan dapat melewati membrane [10]. Senyawa TBP dan D2EHPA untuk pemisahan perak (Ag) dari limbah cair foto rontgen menggunakan metode Supported Liquid Membrane (SLM), hasil yang didapatkan \% pemisahan sebesar $21,33 \%$ pada limbah pengenceran 100 kali [7].

Pada penelitian ini dilakukan dengan pengambilan perak metode ekstraksi pelarut dengan teknik membran cair emulsi (emulsion liquid membranedisebut ELM). Dengan campuran pembawa D2EHPA-TBP. Keutungan teknik ini memiliki selektivitas, efisiensi sistem yang tinggi, dan mengurangi penggunaan jumlah pelarut [11] [4].

\section{Metode Penelitian}

\subsection{Alat dan Bahan}

Alat yang digunakan dalam penelitian ini adalah Magnetic stirrer, Peralatan gelas standar, Spektrofotometri Serapan Atom (Perkin Elmer 5100 PC), pH meter Metrohm

Bahan yang digunakan dalam penelitian ini adalah $\mathrm{AgNO}_{3}, \mathrm{H}_{2} \mathrm{SO}_{4}, \mathrm{~K}_{2} \mathrm{Cr}_{2} \mathrm{O}_{7}, \mathrm{CuSO}_{4} .5 \mathrm{H}_{2} \mathrm{O}$, $\mathrm{NaOH}$ (G.R.), Minyak tanah fraksi 200-220 ${ }^{\circ} \mathrm{C}$, D2EHPA (SIGMA), TBP (SIGMA), $\mathrm{HCl}, \mathrm{HNO}_{3}$ (G.R), SPAN-80 (sorbitan monoleat) (SIGMA)

\subsection{Cara Kerja}

\subsubsection{Pembuatan Larutan Umpan $\mathrm{Ag}^{+} \mathbf{1 0 0}$ ppm}

Emulsi dibuat dengan mencampurkan larutan fasa internal 0,1 $\mathrm{M} \mathrm{HNO}_{3}$ dengan fasa membran (organik) yang terdiri dari pembawa TBP, D2EHPA atau campurannya dengan zat pengemulsi $10 \%$ SPAN-80 (sorbitan monooleat) dan diaduk selama 20 menit, lalu didiamkan 3 menit sebelum dicampur dengan fasa umpan. Perbandingan fasa internal dan membran/fasa organik dibuat konstan yaitu $1: 1$, sedangkan perbandingan fasa emulsi dengan fasa umpan juga dibuat konstan 1:10. Pelarut pembawa yang dipakai adalah minyak tanah. Minyak tanah sebelum digunakan didistilasi dulu dengan menggunakan $\mathrm{H}_{2} \mathrm{SO}_{4}$ pekat dengan perbandingan volume 100:1, fraksi yang digunakan sebagai pelarut adalah fraksi dengan titik didih $200-220^{\circ} \mathrm{C}$. $\mathrm{pH}$ di fasa umpan dan penerima dibuat konstan yaitu 3 dan 1 , pengukuran $\mathrm{pH}$ dilakukan dengan menggunakan $\mathrm{pH}$ meter Metrohm. Perlakuan fasa umpan ke dalam fasa emulsi dilakukan di dalam gelas beaker dan diaduk dengan kecepatan konstan selama 15 menit dengan menggunakan magnetic stirrer. Fasa umpan diambil setelah didiamkan sekitar 3 menit. Setelah pengadukan diukur $\mathrm{pH}$ fasa umpan dan kadar ion logam fasa umpan diukur dengan AAS Perkin Elmer 5100 dan Hitachi. Emulsi dipisahkan dari fasa umpan dan dilakukan tahap deemulsifikasi (pendiaman, pemanasan dan pengadukan). Fasa air hasil deemulsifikasi diukur $\mathrm{pH}$-nya.

\subsubsection{Penyiapan ELM (Pembuatan Emulsi)}

Distilasi kerosen diambil fraksi $200-220^{\circ} \mathrm{C}$, fraksi ini digunakan sebagai pelarut TBPD2EHPA. Fasa organik (TBP:D2EHPA dalam minyak tanah) diaduk dengan kecepatan konstan selama 10 menit sambil ditambahkan surfaktan SPAN-80 sampai mencapai kadar $10 \%$. Lalu dicampurkan dengan fasa internal $0,1 \mathrm{M} \mathrm{HNO}_{3}$ dan diaduk selama 20 menit.Hasil pengadukan berupa emulsi w/o dan siap didispersikan ke fasa umpan.

\subsubsection{Pengaruh Variabel Pembawa terhadap Persen Pengambilan Perak dari Larutan Perak nitrat}

Pengambilan perak dari larutan perak nitrat dilakukan dengan pembawa D2EHPA $1 \mathrm{M}$. Pengambilan perak dari larutan perak nitrat dilakukan dengan pembawa D2EHPA-TBP $1 \mathrm{M}$ (4:1). Pengambilan perak dari larutan perak nitrat dilakukan dengan pembawa TBP $1 \mathrm{M}$.

\subsubsection{Pengaruh Variabel Pembawa terhadap Persen Pengambilan Perak dari Larutan Peraktiosulfat}

Pengambilan perak dari larutan peraktiosulfat dilakukan dengan pembawa D2EHPA $1 \mathrm{M}$. Pengambilan perak dari larutan peraktiosulfat dilakukan dengan pembawa D2EHPA-TBP $1 \mathrm{M}$ (4:1). Pengambilan perak dari larutan peraktiosulfat dilakukan dengan pembawa TBP 1 $\mathrm{M}$

\subsubsection{Pengaruh Logam $\mathrm{Cu}$ (II) dan $\mathbf{C r}$ (VI) Terhadap Persen Pengambilan Perak dari Larutan Perak Nitrat}

Pengambilan perak dari larutan perak nitrat yang mengandung logam $\mathrm{Cu}(\mathrm{II})$ dan $\mathrm{Cr}(\mathrm{VI})$ masing-masing $10 \mathrm{ppm}$. Pengambilan perak dari larutan perak nitrat yang mengandung logam $\mathrm{Cu}(\mathrm{II})$ dan $\mathrm{Cr}(\mathrm{VI})$ masing-masing 25 ppm 


\subsubsection{Pengaruh Logam $\mathrm{Cu}$ (II) dan $\mathrm{Cr}$ (VI) Terhadap Persen Pengambilan Perak dari Larutan Perak Tiosulfat}

Pengambilan perak dari larutan perak nitrat yang mengandung logam $\mathrm{Cu}(\mathrm{II})$ dan $\mathrm{Cr}$ (VI) masing-masing $10 \mathrm{ppm}$. Pengambilan perak dari larutan perak nitrat yang mengandung logam $\mathrm{Cu}(\mathrm{II})$ dan $\mathrm{Cr}(\mathrm{VI})$ masing-masing 25 ppm.

\subsubsection{Pengambilan Logam Perak dari Limbahnya (Cuci/Cetak Foto dan Laboratorium)}

Hasil kondisi optimal yang diproleh dari tahaptahap sebelumnya digunakan untk melakukan pengambilan perak dari limbah cuci/cetak foto dan laboratorium.

\subsubsection{Deemulsifikasi}

Fasa emulsi yang dikumpulkan diemulsifikasi. Deemulsifikasi dilakukan setelah fasa emulsi terpisah dari fasa umpan, lalu fasa emulsi diperlakukan dengan bebarapa cara yaitu: pengadukan, pemanasan, dan pendiaman.

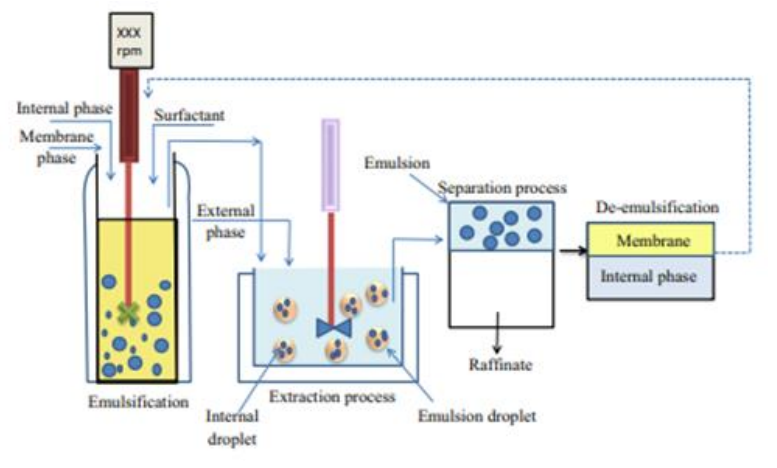

Gambar 1. Mekanisme Emulsi Liquid Membrane (ELM) [10]

\section{Hasil Dan Pembahasan}

\subsection{Efektifitas Pembawa terhadap Persen Pengambilan Perak dari Larutan Perak nitrat dan Peraktiosulfat}

Pada tahap ini dilakukan pengambilan perak nitrat dan peraktiosulfat secara terpisah dengan menggunakan pembawa D2EHPA $1 \mathrm{M}$, D2EHPATBP $1 \mathrm{M}$, D2EHPA-TBP 0,25 M, dan TBP $1 \mathrm{M}$ (masing-masing dengan SPAN-80 sebanyak 10\%) sehingga dapat diketahui efektifitas pembawa terhadap persen pengambilan perak dari larutan perak nitrat maupun dari larutan peraktiosulfat.Hasil pengamatan untuk eksperimen pengambilan perak dari larutan perak nitrat dan larutan peraktiosulfat (limbah buatan) adalah sebagai berikut:
Tabel 1. Persen pengambilan perak dari larutan perak nitrat dan peraktiosulfat dengan variasi pembawa

\begin{tabular}{|l|c|c|}
\hline \multirow{2}{*}{ Pembawa } & \multicolumn{2}{|c|}{$\begin{array}{c}\text { Persen pengambilan } \\
\text { perak }\end{array}$} \\
\cline { 2 - 3 } & $\begin{array}{c}\text { Perak } \\
\text { nitrat (\%) }\end{array}$ & $\begin{array}{c}\text { Peraktio } \\
\text { sulfat (\%) }\end{array}$ \\
\hline D2EHPA 1 M & 64,48 & 25,57 \\
D2EHPA-TBP 1 M & 65,65 & 88,19 \\
D2EHPA-TBP 0,25 M & 96,49 & 82,76 \\
\hline
\end{tabular}

Berdasarkan tabel 1 terlihat bahwa persen pengambilan perak dari larutan perak nitrat dengan pembawa D2EHPA $1 \mathrm{M}$ maupun dengan pembawa D2EHPA-TBP $1 \mathrm{M}$ memberikan hasil yang relatif sama, hasil yang lebih besa diperoleh ketika digunakan pembawa D2EHPA-TBP 0,25 M. Hal ini kemungkinan terjadi karena valensi Ag positif 1 sehingga peran TBP yang merupakan pembawa netral menjadi kecil. Persen pengambilan dengan pembawa D2EHPA-TBP naik ketika digunakan campuran pembawa dengan konsentrasi 0,25 M, kemungkinannya karena pengaruh viskositas pembawa D2EHPA-TBP terhadap transpor logam cukup tinggi sehingga ketika digunakan pembawa D2EHPA-TBP dengan konsentrasi yang lebih encer (viskositas menurun) yaitu 0,25 M persen pengambilan meningkat. Hal ini sesuai dengan persamaan Stokes-Einstein dimana difusi berbanding terbalik dengan viskositas.

Hasil yang berbeda terjadi pada pengambilan perak dari larutan peraktiosulfat, penggunaan pembawa D2EHPA-TBP menghasilkan persen pengambilan yang jauh lebih tinggi daripada persen pengambilan dengan pembawa D2EHPA 1 M. Kecilnya persen pengambilan perak dari larutan peraktiosulfat dengan pembawa D2EHPA kemungkinan karena sifat D2EHPA yang merupakan penukar kation sedangkan peraktiosulfat bermuatan negatif. Dengan demikian untuk sampel berupa peraktiosulfat peran pembawa netral TBP menjadi signifikan terhadap besarnya persen transpor.

Pengambilan perak dari perak nitrat maupun dari peraktiosulfat dengan menggunakan pembawa TBP $1 \mathrm{M}$ gagal dilakukan karena emulsi dengan pembawa TBP tidak dapat terbentuk, meskipun konsentrasi SPAN-80 dinaikkan sampai $20 \%$. Hal ini kemungkinan terjadi karena beda kepolaran yang cukup tinggi antara TBP dengan komponen pembentuk emulsi lainnya, sehingga untuk selanjutnya pengambilan dengan menggunakan pembawa TBP 1 M tidak dilakukan.

Dari Tabel 1 juga dapat disimpulkan bahwa penggunaan pembawa D2EHPA-TBP dalam 
pengambilan perak dari peraktiosulfat menghasilkan efek sinergi. Meskipun pengambilan dengan pembawa TBP tidak bisa dilakukan, tapi dengan melihat kecilnya persen pengambilan perak dari peraktiosulfat dengan menggunakan pembawa D2EHPA $1 \mathrm{M}$ dan fakta bahwa TBP merupakan pembawa netral (berbeda dengan D2EHPA yang merupakan penukar kation) terdapat indikasi mengenai adanya efek sinergi pada pengambilan perak dari peraktiosulfat menggunakan pembawa D2EHPATBP.Menurut Lee (1996) reaksi yang terjadi antara perak dengan pembawa D2EHPA adalah sebagai berikut:

$\mathrm{Ag}^{+}+(\mathrm{HR})_{2} \rightarrow \mathrm{AgR}(\mathrm{HR})+\mathrm{H}^{+}$.

\subsection{Pengaruh Logam $\mathrm{Cu}(\mathrm{II})$ dan $\mathrm{Cr}$ (VI) terhadap Persen Pengambilan Perak dari Larutan Perak nitrat dan Peraktiosulfat}

Pada tahap ini dilakukan pengambilan perak dari larutan perak nitrat dan larutan peraktiosulfat yang masing-masing mengandung campuran logam $\mathrm{Cu}(\mathrm{II})$ dan $\mathrm{Cr}(\mathrm{VI})$ sehingga dapat diketahui tingkat selektifitas pembawa maupun efek dari $\mathrm{Cu}(\mathrm{II})$ dan $\mathrm{Cr}(\mathrm{VI})$ terhadap persen pengambilan perak. Dari eksperimen sebelumnya diperoleh kesimpulan bahwa secara umum pengambilan lebih efektif dengan pembawa D2EHPA-TBP, dengan demikian pada tahap ini hanya dilakukan pengambilan dengan pembawa tersebut.Hasil pengamatan untuk eksperimen pengambilan perak dari larutan perak nitrat dan larutan peraktiosulfat dengan adanya $\mathrm{Cu}(\mathrm{II})$ dan $\mathrm{Cr}(\mathrm{VI})$ (limbah buatan) ditampilkan dalam tabel dibawah ini:

Tabe1 2. Persen pengambilan perak dari larutan perak nitrat dan peraktiosulfat dengan adanya $\mathrm{Cu}(\mathrm{II})$ dan $\mathrm{Cr}(\mathrm{VI})$

\begin{tabular}{|c|c|c|c|}
\hline \multirow[t]{2}{*}{$\begin{array}{l}\text { Larutan } \\
\text { sampel }\end{array}$} & \multicolumn{3}{|c|}{$\begin{array}{l}\text { Persen pengambilan perak dengan } \\
\text { adanya } \mathrm{Cu}(\mathrm{II}) \text { dan } \mathrm{Cr}(\mathrm{VI})\end{array}$} \\
\hline & 0 ppm (\%) & 10 ppm (\%) & $25 \mathrm{ppm}(\%)$ \\
\hline $\begin{array}{l}\text { perak } \\
\text { nitrat }\end{array}$ & 65,65 & 56,17 & 39,82 \\
\hline $\begin{array}{l}\text { Peraktio } \\
\text { sulfat }\end{array}$ & 88,19 & 87,42 & 94,93 \\
\hline
\end{tabular}

Tabe1 3. Persen Cu(II) dan Cr(VI) yang ikut terambil

\begin{tabular}{lllll}
\hline $\begin{array}{l}\text { Larutan } \\
\text { sampel }\end{array}$ & \multicolumn{4}{c}{ Konsentrasi logam yang ditambahkan } \\
& 10 & \multicolumn{2}{c}{$\begin{array}{c}\text { Cu(II) } \\
\mathrm{Cr}(\mathrm{VI})\end{array}$} \\
& $\mathrm{ppm}(\%)$ & $\mathrm{ppm}(\%)$ & $\begin{array}{l}10 \mathrm{ppm} \\
(\%)\end{array}$ & $\begin{array}{l}25 \\
\mathrm{ppm}(\%)\end{array}$ \\
\hline $\begin{array}{l}\text { perak } \\
\text { nitrat }\end{array}$ & 55 & 61,71 & 50,19 & 30 \\
$\begin{array}{l}\text { Peraktio } \\
\text { sulfat }\end{array}$ & 57,6 & 78,08 & 15,86 & 42,9 \\
\hline
\end{tabular}

Tabel 2 dan Tabel 3 memperlihatkan bahwa bahwa penurunan persen pengambilan perak dari larutan perak nitrat terjadi karena senyawa pembawa tidak hanya mengekstrak perak tapi juga logam $\mathrm{Cu}(\mathrm{II})$ dan $\mathrm{Cr}(\mathrm{VI})$. Sedangkan adanya logam $\mathrm{Cu}(\mathrm{II})$ dan $\mathrm{Cr}(\mathrm{VI})$ dalam larutan peraktiosulfat akan menaikkan persen pengambilan.

\subsection{Pengambilan Perak dari Limbah Cuci/Cetak Foto}

Pada eksperimen ini, membandingkan pengambilan perak dari limbah lab dengan acifix yang ditunjukkan pada Tabel 4. Pengambilan perak dari limbah cuci/cetak foto (acifix) menggunakan emulsi dengan kadar SPAN-80 sebesar $20 \%$ dan limbah acifix diencerkan sampai 10 kali. Sedangkan limbah laboratorium analitik dipekatkan hingga separoh volume semula logam perak yang diperoleh sebesar 2,9 ppm, jumlah yang cukup kecil jika dibandingkan dengan konsentrasi perak dalam limbah acifix.

Tabel 4. Persen pengambilan perak dari limbah acifix dan laboratorium.

\begin{tabular}{|c|c|c|c|}
\hline \multirow[t]{2}{*}{ Pembawa } & \multirow[t]{2}{*}{$\begin{array}{l}\text { SPAN- } \\
80\end{array}$} & \multicolumn{2}{|c|}{$\begin{array}{lr}\text { Persen pengambilan } \\
\text { perak dari limbah } \\
\text { acifix } & \text { dan } \\
\text { laboratorium. }\end{array}$} \\
\hline & & acifix & $\begin{array}{l}\text { Limbah } \\
\text { lab. }\end{array}$ \\
\hline D2EHPA 1M & $20 \%$ & $88,14 \%$ & - \\
\hline $\begin{array}{l}\text { D2EHPA-TBP } \\
0,25 \mathrm{M}\end{array}$ & $20 \%$ & $87,87 \%$ & - \\
\hline $\begin{array}{l}\text { D2EHPA-TBP } \\
1 \mathrm{M}\end{array}$ & $20 \%$ & $89,26 \%$ & $94,52 \%$ \\
\hline $\begin{array}{l}\text { D2EHPA-TBP } \\
1 \mathrm{M}\end{array}$ & $30 \%$ & $89,27 \%$ & - \\
\hline
\end{tabular}

Berbeda dengan pengambilan perak dari limbah buatan, baik dari larutan perak nitrat maupun dari larutan peraktiosulfat, variasi pembawa yang digunakan ternyata tidak menghasilkan persen pengambilan logam yang signifikan. Seharusnya, dengan memperhatikan data yang diperlihatkan pada tabel 1, pengambilan akan maksimal pada penggunaan pembawa D2EHPA-TBP $1 \mathrm{M}$ dan persen pengambilan terkecil akan diperoleh pada penggunaan pembawa D2EHPA $1 \mathrm{M}$. Sebaliknya, pada tabel 4 menunjukkan hasil yang menyimpang, pembawa D2EHPA ternyata mampu mengambil perak dengan hasil yang relatif sama dengan pembawa D2EHPA-TBP.

\subsection{Deemulsifikasi}

Fasa emulsi yang telah dipisahkan dari fasa penerima, diemulsifikasi dengan tiga cara yaitu, pengadukan, pemanasan, dan pendiaman. 
Seperti yang telah diperkirakan sebelumnya, tahap deemulsifikasi cukup sulit. Fasa emulsi tidak pecah meskipun telah diaduk selama kurang lebih tiga jam, pemanasan selama 5 menit juga tidak mampu memecah emulsi. Sedangkan dengan cara pendiaman fasa emulsi baru pecah setelah 1 minggu. Hal ini menunjukkan bahwa emulsi yang terbentuk sangat stabil. Kestabilan emulsi adalah faktor penting sekaligus permasalahan dalam teknik ELM.

\subsection{Perubahan pH di fasa umpan dan penerima}

Peran $\mathrm{pH}$ terhadap keberhasilan pengambilan logam dengan menggunakan pembawa D2EHPA sangat penting. Secara teoritis D2EHPA akan berikatan dengan logam dan melepaskan ion hidrogen, dengan demikian ion hidrogen dalam fasa penerima akan berperan sebagai pengganti ion logam yang semula berikatan dengan pembawa (atau dengan kata lain dalam fasa penerima terjadi pertukaran ion logam dari pembawa dengan ion hidrogen dari fasa penerima) kemudian pembawa akan melepaskan kembali ion $\mathrm{H}$ tersebut ke fasa umpan sebagai pengganti ion logam yang berikatan dengan senyawa pembawa. Dengan demikian diperlukan adanya gradien $\mathrm{pH}$ antara fasa umpan dan fasa penerima sebagai driving force terjadinya transpor, dalam penelitian ini fasa umpan diatur pada $\mathrm{pH} 3$ dan fasa penerima pada $\mathrm{pH} 1$. Adanya fenomena pertukaran ion hidrogen tersebut dibuktikan dengan adanya perubahan $\mathrm{pH}$ di fasa umpan dan penerima, sesuai tabel berikut:

Tabel 5. Perubahan $\mathrm{pH}$ di fasa umpan dari sampel perak nitrat

\begin{tabular}{lcc}
\hline \multicolumn{1}{c}{ Pembawa } & \multicolumn{2}{c}{ pH fasa umpan } \\
& Awal & Akhir \\
\hline D2EHPA 1 M & 3,02 & 1,86 \\
D2EHPA-TBP 1 M & 3,00 & 1,62 \\
D2EHPA-TBP 0,25 M & 3,01 & 1,84 \\
\hline
\end{tabular}

Tabel 6. Perubahan $\mathrm{pH}$ di fasa umpan dari sampel peraktiosulfat

\begin{tabular}{lcc}
\hline \multicolumn{1}{c}{ Pembawa } & \multicolumn{2}{c}{ Aw fasa umpan } \\
& Awal & Akhir \\
\hline D2EHPA 1 M & 3,02 & 1,93 \\
D2EHPA-TBP 1 M & 3,00 & 1,88 \\
D2EHPA-TBP 0,25 M & 3,02 & 1,90 \\
\hline
\end{tabular}

Tabel 7. Perubahan $\mathrm{pH}$ di fasa umpan dari sampel $\mathrm{AgNO}_{3}$ dengan adanya $\mathrm{Cu}(\mathrm{II})$ dan $\mathrm{Cr}(\mathrm{VI})$

\begin{tabular}{lclc}
\hline \multirow{2}{*}{ Pembawa } & Cu(II) & dan & \multicolumn{2}{c}{ pH fasa umpan } \\
& Cr(VI) (ppm) & Awal & Akhir \\
\hline D2EHPA- & 10 & 2,93 & 2,01 \\
TBP 1 M & 25 & 2,90 & 2,04 \\
& & & \\
\hline
\end{tabular}

Tabel 8. Perubahan $\mathrm{pH}$ di fasa umpan dari sampel peraktiosulfat dengan adanya $\mathrm{Cu}(\mathrm{II})$ dan

\begin{tabular}{|c|c|c|c|}
\hline \multicolumn{4}{|c|}{$\mathrm{Cr}(\mathrm{VI})$} \\
\hline \multirow{2}{*}{ Pembawa } & $\mathrm{Cu}(\mathrm{II}) \quad$ dan & \multicolumn{2}{|c|}{ pH fasa umpan } \\
\hline & $\mathrm{Cr}(\mathrm{VI})$ (ppm) & Awal & Akhir \\
\hline D2EHPA- & 10 & 3,03 & 2,06 \\
\hline ТВР $1 \mathrm{M}$ & 25 & 3,01 & 2,08 \\
\hline
\end{tabular}

Tabel 9. Perubahan $\mathrm{pH}$ di fasa umpan dari sampel limbah acifix

\begin{tabular}{lccc}
\hline \multicolumn{1}{c}{ Pembawa } & \multirow{2}{*}{ SPAN-80 } & \multicolumn{2}{c}{ pH fasa umpan } \\
& & Awal & Akhir \\
\hline D2EHPA 1 M & $20 \%$ & 3,03 & 2,61 \\
D2EHPA-TBP 0,25 & $20 \%$ & 3,00 & 2,67 \\
M & & & \\
D2EHPA-TBP 1 M & $20 \%$ & 3,01 & 2,69 \\
D2EHPA-TBP 1 M & $30 \%$ & 3,00 & 2,64 \\
\hline
\end{tabular}

Tabel 10. Perubahan $\mathrm{pH}$ di fasa umpan dari sampel limbah laboratorium

\begin{tabular}{cccc}
\hline \multirow{2}{*}{ Pembawa } & \multirow{2}{*}{ SPAN-80 } & \multicolumn{2}{c}{ pH fasa umpan } \\
& & Awal & Akhir \\
\hline D2EHPA-TBP 1 M & $20 \%$ & 3,02 & 2,88 \\
\hline
\end{tabular}

$\mathrm{pH}$ akhir fasa umpan turun karena saat pembawa berada dalam fasa umpan akan melepaskan ion $\mathrm{H}$ dan mengikat ion Ag. Saat pembawa (yang sudah berikatan dengan ion $\mathrm{Ag}$ ) berada di dalam fasa penerima akan melepaskan ion logam dan mengikat ion $\mathrm{H}$ sehingga $\mathrm{pH}$ fasa penerima naik. Kenaikan $\mathrm{pH}$ di fasa penerima dari beberapa sampel ditampilkan dalam Tabel 11.

Tabel 11. Perubahan $\mathrm{pH}$ di fasa penerima dari beberapa sampel

\begin{tabular}{|c|c|c|c|c|}
\hline \multirow{2}{*}{$\begin{array}{c}\text { Pembawa } \\
(1 \mathrm{M})\end{array}$} & \multirow{2}{*}{$\begin{array}{c}\text { SPAN } \\
-80\end{array}$} & \multirow[t]{2}{*}{ Sampel } & \multicolumn{2}{|c|}{$\begin{array}{c}\mathrm{pH} \text { fasa } \\
\text { penerima }\end{array}$} \\
\hline & & & Awal & Akhir \\
\hline D2EHPA & $10 \%$ & $\mathrm{AgNO}_{3}$ & 1,08 & 1,65 \\
\hline D2EHPA-TBP & $10 \%$ & $\mathrm{AgNO}_{3}$ & 1,08 & 1,67 \\
\hline D2EHPA & $10 \%$ & $\mathrm{Ag}\left(\mathrm{S}_{2} \mathrm{O}_{3}\right)_{2}{ }^{3-}$ & 1,08 & 1,65 \\
\hline D2EHPA-TBP & $10 \%$ & $\mathrm{Ag}\left(\mathrm{S}_{2} \mathrm{O}_{3}\right)_{2}{ }^{3-}$ & 1,08 & 1,85 \\
\hline D2EHPA-TBP & $30 \%$ & Acifix & 1,08 & 1,92 \\
\hline
\end{tabular}

\section{Kesimpulan}

Penggunaan pembawa D2EHPA-TBP lebih efektif untuk mengambil perak dari larutan $\mathrm{Ag}\left(\mathrm{S}_{2} \mathrm{O}_{3}\right)_{2}{ }^{3-}$ dari pada perak dari larutan $\mathrm{Ag}^{+}$. Penggunaan pembawa D2EHPA-TBP untuk pengambilan perak dari larutan $\mathrm{Ag}\left(\mathrm{S}_{2} \mathrm{O}_{3}\right)_{2}{ }^{3-}$ menghasilkan efek sinergi. Pembawa D2EHPATBP (sinergi) relatif selektif terhadap logam perak daripada $\mathrm{Cu}(\mathrm{II})$ dan $\mathrm{Cr}(\mathrm{VI})$.

\section{Ucapan Terimakasih}

Penulis mengucapkan terimakasih kepada Universitas Diponegoro atas didanainya penelitian ini. 


\section{Daftar Pustaka}

[1] Townshend, Alan, Encyclopedia of analytical science, Academic Press, 1995,

[2] Fernanda, Decky Danuarta, Ni Nyoman Rupiasih, Nyoman Wendri, Ni Wayan Eri Sandriani, Kitosan sebagai Adsorben Perak (Ag) pada Limbah Fixer Fotografi Rumah Sakit, Buletin Fisika Vol, 20, 1, (2019), 6-10

[3] Suharyono, Suharyono, Alifah Mubarokah, Bioreduksi Limbah $\mathrm{AgNO}_{3}$ Sisa Proses Pewarnaan Perak Memanfaatkan Eksopolisakarida Bacillus subtilis, Indonesian Journal of Laboratory, 2, 3, (2020), 27-34 https://doi.org/10.22146/ijl.v2i3.57265

[4] Santoso, Imam, Recovery Perak (I) dari Limbah Cuci/Cetak Foto dengan Menggunakan Teknik Membran Cair Emulsi, (2000)

[5] Shankar, S., S. V. More, R. Seeta Laxman, Recovery of Silver from Waste X-Ray Film by Alkaline Protease from Conidiobolus coronatus, Kathmandu university journal of science, engineering and technology, 6, 1, (2010), 60-69 https://doi.org/10.3126/kuset.v6i1.3311

[6] Modi, Ashish, Kishan Shukla, Jaimin Pandya, Kalpesh Parmar, Extraction of Silver from Photographic Waste, International Journal of Emerging Technology and Advanced Engineering, 2, 11, (2012), 599606

[7] Kurniasih, Yeti, Ahmadi Ahmadi, Baiq Asma Nufida, Pemisahan Perak dari Limbah Fotorontgen dengan Teknik Membran Cair
Berpendukung Menggunakan Pengembang Gabungan TBP dan D2EHPA, Hydrogen: Jurnal Kependidikan Kimia, 8, 1, (2020), 4046

https://doi.org/10.33394/hjkk.v8i1.2582

[8] Djunaidi, Muhammad Cholid, Abdul Haris, Pemisahan Logam Berat Menggunakan Membran Cair Berpendukung dengan Variabel Konsentrasi Ion Logam dan PH Fasa Umpan, Jurnal Kimia Sains dan Aplikasi, 6, 2 (2003), $1-4$ https://doi.org/10.14710/jksa.6.2.1-4

[9] Permatasari, Sri Intan, Muhammad Cholid Djunaidi, Habibi Habibi, Pemisahan Ion Logam Krom dari Limbah Elektroplating Menggunakan Polieugenol dengan Teknik Membran Cair, Analit: Analytical and Environmental Chemistry, 4, 2, (2019), 14-29 https://doi.org/10.23960/aec.v4.i2.2019.p1 4-29

[10] Hussein, Maad A., Ahmed A. Mohammed, Mohammed A. Atiya, Application of Emulsion and Pickering Emulsion Liquid Membrane Technique for Wastewater Treatment: An Overview, Environmental Science and Pollution Research, 26, 36, (2019), 3618436204 https://doi.org/10.1007/s11356019-06652-3

[11] Bartsch, Richard A., J. Douglas Way, Chemical Separations with Liquid Membranes: An Overview, ACS Symposium Series, 642, 1, (1996), 1-10 https: / / doi.org/10.1021/bk-19960642.ch001 